\title{
The application of a schema to Late Gothic heritage: creating a digital model for a spatio-temporal study in Andalusia
}

\author{
P. Ferreira Lopes \& F. Pinto Puerto \\ Research Group HUM799, Department of Architectural Graphic \\ Expression, University of Seville, Spain
}

\begin{abstract}
Late Gothic architecture was produced during the late 15th and early 16th centuries in a "supranational" European context in which the rich interaction of professionals created a map of exchange with a significant impact on the territory. This historical period can therefore be viewed as a complex system shaped by the activities of various actors and phenomena. Our methodology includes geographical analysis and visualisations of historical data - geolocalised primary sources - and allows us to generate new hypotheses and interpretations about this historical period. This project proposes a new perspective for studying transit in Andalusia during the Modern Era, based on the creation of a digital model of Late Gothic heritage using the spatial data infrastructure currently being generated by the International Late Gothic Network (www.tardogotico.es). Our research examines four geohistorical elements - roads, fluxes, buildings and professionals - and uses a methodology that may have applications in the future for many fields of heritage research and management. This paper presents the initial results of this innovative way of researching cultural heritage.

Keywords: Late Gothic heritage in Andalusia, digital model, heritage management and research, geographic information system, geohistorical data infrastructure.
\end{abstract}

\section{Introduction}

This paper has been produced in connection with the Strategies for Heritage Knowledge research currently being conducted by Group HUM799 [1], which is based on the premise of a possible convergence, in practical terms, between 
diverse and currently disconnected fields of knowledge that impact on architectural heritage (such as documentary, archaeological, architectural, visual, analytical and economic data) and on cultural heritage in general. Heritage knowledge must draw on information from different disciplines, which when interrelated and juxtaposed will allow us to obtain a holistic view of the object of our analysis.

In recent decades the dimension of architectural heritage has transcended the purely material and intrinsic view of the object to encompass the cultural significance of the work, irrespective of whether this significance is material or immaterial in its cultural context. Understanding heritage as both the producer and product of a cultural and historical context therefore leads us to reflect on how we might turn a highly specialised and compartmentalised view into an open, dynamic and systematic view.

Many scientific references [2, 3] have argued that cultural heritage is underpinned by several key factors: knowledge, memory, and the traditions and customs created by society. In accordance with our knowledge of cultural heritage, and based on the consideration of space as an essential entity for understanding, identifying and managing this heritage, we expect the creation of a digital model to make it easier to work with a vast quantity of data, collect linked data, formulate a multiscale and multidisciplinary interpretation, link spatial and non-spatial information, generate new forms of visualisation and analysis, and therefore improving the generation of knowledge in general.

According to Capra and Sempau [4], the world should be seen as an integrated whole rather than a collection of parts. Capra considers three different but complementary perspectives of the life phenomenon that can also be applied to architecture: pattern, structure and process. He also stresses the need to think about elements as forming part of a complex system in which they are interdependent and immersed in a cyclical, open process.

Below we offer our findings following our multidisciplinary research combining digital humanities, information systems, cultural heritage and architectural history to create a spatio-temporal digital model for analysing Late Gothic heritage in Andalusia.

The region of Andalusia is the result of the superimposition of numerous cultures that have forged its identity. The countless civilisations that have passed through this land have left their indelible mark, from the Roman domination and the Islamic conquest to the subsequent Christian reconquest. Each of these stages played a role in shaping the region's geography: the border tensions between the kingdoms of Granada and Seville during the course of several centuries gave rise to the construction of a considerable number of military buildings, the exploitation of the natural resources through irrigation systems during Islamic rule, and following the Christian reconquest the organisation of large towns that centralised the social movements and monopolised the most important construction enterprises. Out of this lengthy process we have chosen the period spanning the late 15 th and early 16 th centuries, which was characterised by the consolidation of the borders on the Iberian Peninsula and increasingly important links with Europe through political and cultural expansion, manifested in the 
numerous exchanges between the political leaders, intellectuals, scientists and technicians of the main centres of power. In the field of architecture, these fluxes and influences played a crucial role in consolidating roads, creating centres to produce materials and products, and founding monasteries and cathedrals. The scale acquired by these enterprises was directly responsible for the consolidation of many of today's towns, infrastructures and provincial organisations. One example is Seville Cathedral, the largest Gothic building erected in such a short space of time: just 73 years, between 1433 and 1519. This endeavour required the transportation of stone from $100 \mathrm{~km}$ away by land, river and sea, the construction of docks, cranes and vessels, the excavation of quarries, and a constant flux of master builders, who simultaneously worked on the construction of the main churches in the larger towns of the diocese, repeating the solutions and reproducing the same building processes as those employed in the great cathedral. Meanwhile, the cathedral attracted master builders and craftsmen from all over Europe, from a Normandy at war to the burgeoning Germany. Furthermore, this coincided with the expansion to the New World, a phenomenon in which Seville acquired an extraordinary protagonism and came to be known only a few years later as the "New Rome". Visualising these factors and determining their influence on different scales of architecture would be a very complex task without the new tools and digital models that enable us to relate them in both time and space.

A "spatio-temporal digital model" is understood to represent a view of heritage based on a multiscalar focus comprising the attribute, time and space. Within the Late Gothic context, these three components interconnect different types of entities - professionals, buildings and infrastructures - which, as we see them, interact to transform their context while simultaneously being conditioned by it. As Tufte [5] and Calvino et al. [6] have pointed out, micro and macro readings combined offer a complementary view of the relationships between elements, their space and the events of the past. The digital model of Late Gothic heritage that we are creating will reveal the development of Andalusia as a complex system in this specific historical context, following a long process of reconquest during which two cultures overlapped. Data mining and the visualisation of this data using new digital resources will offer new perspectives and interpretations of the relationships between the production of buildings, as related to space and time, the movement of professionals, knowledge transfer, clusters of buildings, funding structures, the supply of building materials, and transportation.

In light of the aforementioned considerations, this paper proposes the integration of different types of data on different subjects and from different spaces and times to offer a rhizomatic, holistic insight into how the territorial structure of Andalusia developed in the Late Gothic context. Using maps as a medium, we attempt to discover how the structure of Andalusia was shaped during the 15th and 16th centuries. Our research therefore aims to advance the understanding of space as the result of many processes and relationships [7]. Furthermore, the methodology applied in this research can be applied to other historical contexts and even to other disciplines and fields. 


\section{Methodology}

In recent years, a network of researchers in Spain, Portugal and Italy has produced a database on the Late Gothic (www.redtardogotica.es), which to date consists of 2,700 professionals associated with works built in the 15th and 16th centuries. The database includes the provenance of each professional, the bibliography in which he is cited, the time he was active, and his professional category. Using this database and an entity-relationship model, we have implemented a system that offers us the flexibility to describe the spatiotemporal interconnections between the objects stored and create a complex universe of analysis that enables us to establish numerous interrelationships.

The Late Gothic context was characterised by architecture without frontiers, a transnational architecture [8] in which the transfer of knowledge was achieved by the mobility of professionals and the constant sharing of wisdom between architects but also between philosophers, theoreticians, theologians and senior representatives of the state and clergy. Consequently, we can only fully appreciate it by using a methodology that contemplates the activities of the different agents involved in the formation of this architecture, seen as the product and producer of these relationships.

The framework of reference for this project is a historical geography that permits the organisation and visualisation of data relating not only to kingdoms, dioceses, towns, roads and infrastructures, but also to the agents [9] who played an important role in shaping these elements: master builders, stonemasons, monarchs, bishops, patrons, etc. We aim to map these networks [10] in which the essential properties of the different entities are derived from their interactions and interdependence. Our model goes beyond simply analysing the separate parts, and instead offers a view of interconnected systems and sub-systems. The inclusion of a temporal dimension in our maps reveals relationships, routes and objects that were hitherto invisible and disconnected.

The principal aims of the project are as follows: to create an infrastructure of spatial information on the Late Gothic in Andalusia, in line with the European directive INSPIRE to guarantee the interoperability of the data collected; to establish the relationships of identity and knowledge for the agents involved; to create a holistic view of the Late Gothic context in order to generate new interpretations and knowledge; to develop new techniques with applications for other lines of research in the humanities and other fields; to facilitate interdisciplinary research by providing a visual medium to act as the point of convergence between disciplines; to publicise the findings of the project as widely as possible in order to foster a knowledge and appreciation of Andalusia's Late Gothic heritage and promote a holistic view of this heritage; to provide the means for the future inclusion of this regional context in the contexts of the Iberian Peninsula and Europe.

Although we live in the digital age, we are still presented with enormous difficulties when working with historical documents. From an organisational point of view, a project based on such wide and diverse information relies on accuracy - accuracy of the data themselves but also in how they are searched for 
and processed. Furthermore, digitising and processing the data found requires preliminary selection and exhaustive graphic representation, which in our case primarily consists in creating thematic maps of the data.

The first problem posed by this project is precisely the representation of the information we wish to analyse. Since the project encompasses very diverse entities with highly complex relationships, we have been obliged to use an unconventional methodology that enables us to systematically draw crossreferenced conclusions and that may provide a source for other researchers in the future. Our research is therefore open-ended, allowing us to add new information and edit existing data.

The complexity of our project also encompasses different scales, from the architectural object to the geographical context. However, the Late Gothic in Andalusia cannot be viewed in isolation; it must be set within the context of the Iberian Peninsula. Consequently, part of the information gathered must be processed and visualised on a peninsular scale, and part on a regional or Andalusian scale. In this case, the digital model created must comprise several levels of data which selectively represent the most important information. This flexibility may be achieved through two schemas - geographic information systems and graphical visualisation - which have enabled us to systematically represent blocks of interrelated information.

In addition to the spatial factor, time is another consideration in creating the digital model because its representation and processing will affect all the entities in the system. We know that GIS models do not normally include a time factor, offering only a synchronous spatial representation of a specific point of reference in time [11]. However, that does not mean that time cannot be managed through a GIS. In the digital model created for the Late Gothic network, time is being processed in two different ways: by means of entity attributes (such as start and end dates for the construction of buildings), and through temporal layers in order to compare layers from different chronologies - for example, by superimposing them - and understand their transformations. We therefore aim to analyse the changes and connections that have occurred through time in order to obtain knowledge about the possible cause and effect relationships [12].

So what advantages have we gained by applying these tools to our digital model? The first is that we have been able to store, organise and structure a vast and diverse quantity of data. The second is that we now have a model that will enable us to interpret systems on their different scales and obtain a holistic view of their relationships in space and time. And a third advantage is that we can conduct spatial and mathematical analyses, depending on the type of concurrent relationships we want to explore.

We will now describe some of the specific results that we are obtaining in the Digital Model of Andalusia's Late Gothic Heritage project by using geographic information systems and graphical representation. To do this, we will describe some of the information we have worked with to date and the partial results obtained. 


\section{DMALG: digital model of Andalusia's Late Gothic heritage}

The aim of DMALG is to create a new approach to Late Gothic heritage based on the theoretical framework of Lefebvre [13], who proposes observing the network of links, collaborations and conflicts between architectural, geopolitical and social space in order to discover the multiple agents, builders and users of a given space over time.

The digital model of Andalusia's Late Gothic heritage will comprise eight phases: design of the GIS and database; data collection, processing and selection; data analysis and input to database; production of visualisations of the model; assessment of problems encountered; establishment of data interconnections and interrelationships; generation of queries and reports; development of the documentation system; and dissemination of the model. However, these development phases of the project are neither static nor isolated. We know that in a project of this scale, with such a large quantity of data and so many diverse sources, information processing will be constant throughout, as the project takes shape and is restructured. This constitutes further justification for the use of GIS and the generation of a database.

The flexibility of the interface offered by GIS and by the construction of a database has been demonstrated in similar projects $[14,15]$, in which the GIS was established, designed and developed in line with the needs identified during each project. In keeping with the advances in national standards and institutions, DMALG includes guidelines and input data provided by the IECA (Institute of Statistics and Cartography of Andalusia) and the ING (National Geographic Institute) in order to guarantee the compatibility of the digital model created. The data are being created in shapefile format using the ArGIS platform by ESRI. The format of the initial database is Microsoft Excel to permit its translation to a Microsoft Access format. The GIS is being developed in accordance with ISO 19100 and OGC (Open Geospatial Consortium) standards and in line with the recommendations of the INSPIRE and LISIGE (Infrastructures and Geographic Information Services Act) directives.

The data that have been gathered and processed have been used to create a digital model of geographic information that enables us to obtain detailed representations of the relationships between the entities analysed to date. This task has been facilitated by using GIS technology to store, organise and visualise its elements (kingdoms, dioceses, roads, towns, buildings, etc.). Meanwhile, graph-based technologies will enable us to represent the information through relational schemas, which in turn will facilitate the representation of other stored elements (professionals, occupational categories, works, etc.). Graphs not only allow us to highlight these relationships and their significance but, on certain occasions, to quantify them.

One example of the historical information selected and processed to date is the collection of road maps of Spain drawn up by Juan Villuga in 1543, which enables us to visualise the connections between a total of 139 roads that linked the main towns at the time and witnessed the journeys of monarchs and different authorities. The reason for beginning with these maps was that as our first step in 


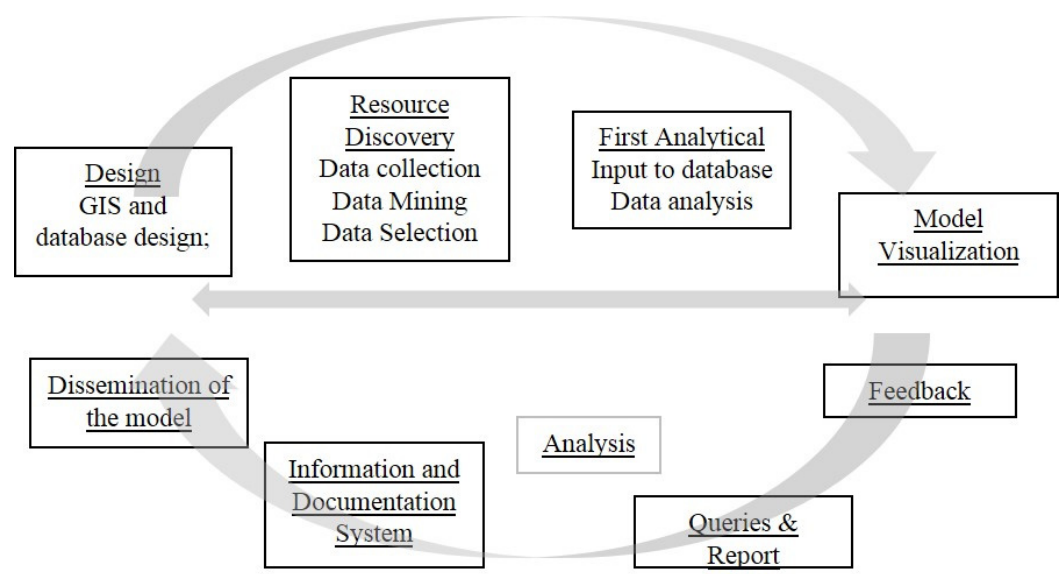

Figure 1: Development phases of the digital model of Andalusia's Late Gothic heritage. As you can see these phases are neither static nor isolated, they are a cyclic mechanism.

the process we needed to visualise the network of roads that existed throughout the Iberian Peninsula during the Late Gothic period in order to understand how the territory was organised, the routes along which materials were transported, and which towns acted as trading centres. To process these data, we have begun with the southern region of the peninsula, which encompasses the present-day region of Andalusia, and we are digitising, georeferencing and vectorising the roads using ArcGIS software. By identifying every route with its arrival and departure points and adjusting the roads to the topography of the territory, we can provide a more reliable visualisation of the possible routes used in the 16th century. Another great advantage of using GIS tools is that we can create visualisations by juxtaposing different historical maps, such as the Nova Descriptio Hispanie from 1553 and the Nova Tabula Hispaniae from 1482. This helps us to verify, for example, the towns represented and the mountains and rivers, and to perceive which elements were represented in a more significant way. These data enable us to juxtapose Roman, medieval and modern communication routes and to perceive how their development conditioned the construction of major architectural works. We can also assess the quality of works through its influences and the greater or lesser presence of professionals, and the proximity to or distance from the main production and funding centres.

On a peninsular scale, using the historical maps obtained from the ecclesiastical dictionary of Spain in the 15th and 16th centuries [16], we can visualise the development and transformation of the dioceses, which will provide information about the interrelationships between the funding for works, the characteristics bestowed by the patrons, the management of the works and the gradual formation of the territory. Furthermore, we will also be able to juxtapose these with the dividing layer of the five kingdoms that existed in the 
Iberian Peninsula in the 15th century: Aragon, Castile, Navarre, Portugal and Granada. In the case of the division of the kingdoms, we have also been able to link the data to the demographic information for the period. ArcGIS offers powerful analysis tools which, coupled with the database, will enable us to integrate the information and generate more information by interrelating and analysing the data stored.

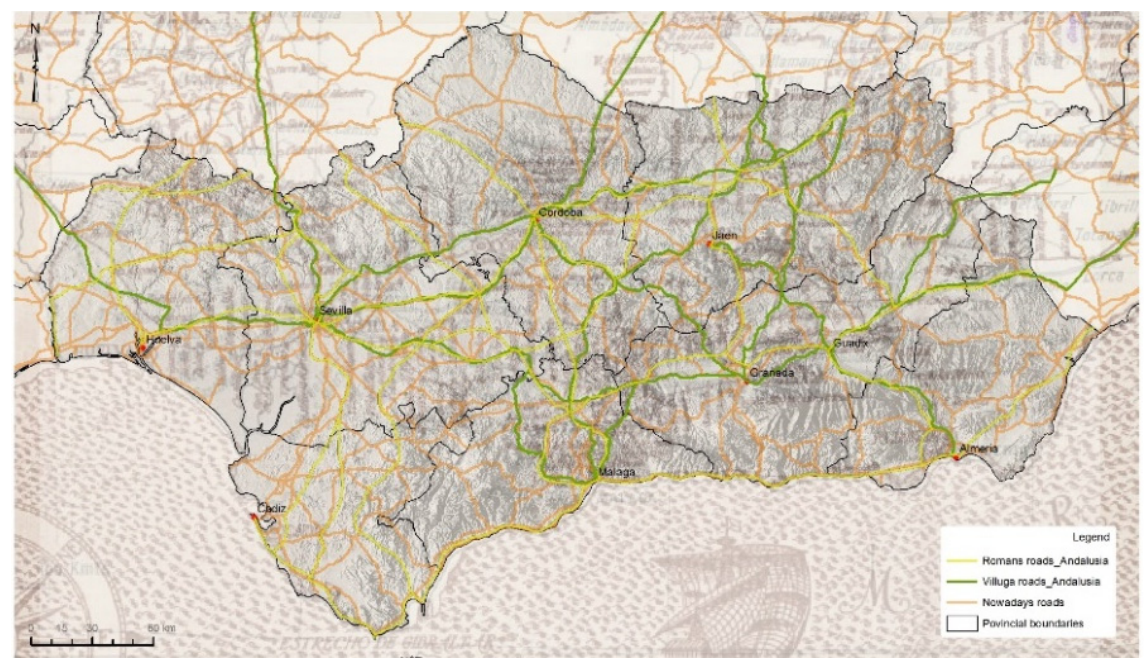

Figure 2: The map shows the juxtaposition of ancient cartography - Nova Descriptio Hispanie 1553 and Nova Tabula Hispaniae de 1482 and the layer of Juan Villuga roads. Roman and existing roads also can be seen.

With regard to the data related to the professionals of the period that have been uploaded to the tardogótico.es database, we have begun to process the information on those who worked on the construction of Seville Cathedral, based on our belief that this work had a significant impact on Andalusia's territory [17, 18].

Using the database of Seville Cathedral professionals, which is structured in CSV format and includes ID numbers, a hierarchical classification system and related attributes, we have created a series of graphs to obtain a preliminary visualisation of the relationships between professionals, works, times and categories, grouping clusters of data in this complex network by means of nodes and edges.

\section{First conclusions and recommendations}

The conclusions we have drawn from our research are still provisional, but we can at least mention some of the ones that have a bearing on the theme of this 


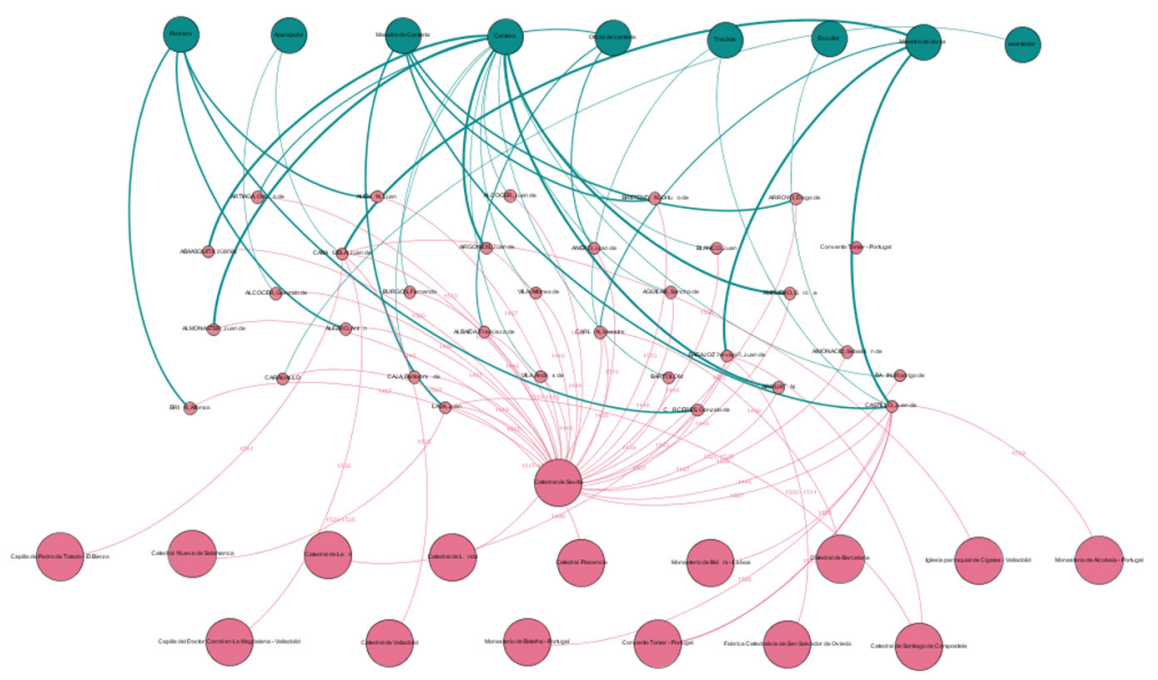

Figure 3: The graph shows the relations between some of those who worked on the construction of Seville Cathedral (minor nodes), their professional category (middle nodes - top of the image) and the others building that they participate in the construction (major nodes).

gathering. 1) We can only obtain a more complete and flexible understanding of the Late Gothic phenomenon by creating a body of knowledge that combines both space and time. The interpretation of a place at a particular moment in time requires a precise understanding of the chronology of how that place developed; in other words, we need to understand its historical process. And we can only do this by establishing links between the diverse histories, events, actors and places that played a role in the process. The production of the place, with all its entities, is in and of itself a great laboratory. This makes consideration of the spatial dimension indispensable, because it is here that the different histories coexist and impact one another. At the same time, the scenario provided by the visualisation of different phenomena is dynamic, active and generative. 2) It would be impossible to carry out this project without the large database created by the Late Gothic network and without using the new information technologies now available. Clearly, by using GIS for our research we are challenging certain methods for constructing database components based exclusively on a historiographic and documentary approach and demanding new fields: spatiotemporal dimensions and the determination and classification of attributes to define them. 3) Visualising and relating these attributes through an information system on cultural heritage has steered our work in two directions: the creation of systems built around the entities, and the implementation of analyses to observe and interpret their relationships. 4) We can affirm that the new 
information tools will modify the research process. Some of the positive aspects derived from this are as follows: it allows us to develop a holistic view in our research and answer questions that would be impossible to answer otherwise; we can formulate new questions and create new knowledge based on new ideas and investigations stemming from the use of new tools and methods; it allows researchers to share their knowledge; and it makes it easier to link existing lines of research. 5) With regard to the Andalusian Late Gothic, we are still in the process of implementing the necessary data, many of which have arisen from the use of GIS systems. It is crucial that we ask the right questions at this stage, just as it is essential that we involve a large group of researchers, historians, archaeologists, architects and geographers. Our participation in the "Late Gothic Network" and its biannual meetings is proving to be enormously beneficial in this respect thanks to the new topics of debate that have emerged surrounding the use of new technologies.

\section{Acknowledgement}

Related to the project (HAR2012-34571) funded by the Spanish Ministry of Economy and Competitiveness and led by the lecturer Francisco Pinto Puerto.

\section{References}

[1] Research Group HUM799 (University of Seville): Strategies for Heritage Knowledge. http://grupo.us.es/ecphum799/

[2] Faro. The Faro Convention on the Value of Cultural Heritage for Society. Council of Europe. Online. http://conventions.coe.int/Treaty/EN/Treaties /Html/199.htm

[3] Querol, M.A. Manual De Gestión Del Patrimonio Cultural. Madrid: Akal. 2010.

[4] Capra, F., \& Sempau, D., La trama de la vida: Una nueva perspectiva de los sistemas vivos. Barcelona: Anagrama. 1998.

[5] Tufte, E. R. (2006). Envisioning Information (11th print ed.). Cheshire, Conn.: Graphics Press.

[6] Calvino, I., Palma, C., \& Bernárdez, A., Las ciudades invisibles. Madrid: Siruela. 2007.

[7] Corboz, André, El Territorio como Palimpsesto. Lo urbano en 20 autores contemporáneos. Barcelona: Edición UPC. 1983.

[8] García Cuetos, M. P., "Raíces del tardogótico castellano. La arquitectura europea en el contexto del último gótico: ¿una arquitectura paneuropea?" La arquitectura tardogótica castellana entre Europa y América. Madrid: Silex, pp. 17-42. 2011.

[9] Keith D. Lilley, "Urban planning after the Black Death: townscape transformation in the later medieval England (1350-1530)". Urban History, pp. 1-21. 2014. 
[10] Desfiles Serra, A., "La arquitectura del tardogótico en la Corona de Aragón: intercambios y trayectorias". La arquitectura tardogótica castellana entre Europa y América. Madrid: Silex, pp. 459-490. 2011.

[11] Gregory, I., "Using Geographical Information Systems to explore Space and Time in Humanities". (Chapter 11) The Virtual Representation of the Past. Farnham, England; Burlington, VT: Ashgate, pp. 135-146. 2008.

[12] Pequeut, D.J, "Time in GIS and geographical databases". (Chapter 8) Geographical Information Systems: Principles, Techniques, Management, and Applications. New York John Wiley \& Sons, pp. 91-203. 2005.

[13] Lefebvre, H. La producción del espacio. Madrid: Capitan Swing. 2000.

[14] F. Pinto Puerto, R. Angulo Fornos, M. Castellano Román, J.M. Guerrero Vega \& F. Pastor Gil., "Construcción de una base cartográfica para el Conjunto Arqueológico de Itálica”. Revista PH, 77, pp. 116-119. 2010.

[15] Zant J., Quartermaine J. \& Hodgkinson A. The distribution of Waterlogged Deposits in Carlisle: Final Report. Online. http://www.english-heritage.org.uk/publications/distribution-waterloggeddeposits-carlisle/6502 WaterloggedCarlisle_FullRep.pdf

[16] Aldea Vaquero, Q., Marín Martínez, T., \& Vives Gatell, J. Diccionario de historia eclesiástica de España. Madrid: Instituto Enrique Flórez. 1972; 1987.

[17] Jiménez Martín, A., et al. La catedral de Sevilla. Fundación y fábrica de la obra nueva. Seville: Servicio de Publicaciones de la Universidad de Seville. 2006.

[18] Jiménez Martín. A. Anatomía de la catedral de Sevilla. Seville: Diputación de Sevilla. 2013. 